\title{
Heating system for measuring tanks of the cementing unit from the exhaust system of the base chassis
}

\author{
Sergey Kireev ${ }^{1, *}$, Marina Korchagina ${ }^{1}$, Andrey Efimov ${ }^{1}$, and Valentin Stepanov ${ }^{1}$ \\ ${ }^{1}$ Don State Technical University, 344010, 1 Gagarina sq., Rostov-on-Don, Russia
}

\begin{abstract}
The purpose of this article is to increase the efficiency of the design process and reduce the cost of field experiments by using numerical analysis methods of the dimensional capacity heating efficiency of the internal combustion engine exhaust system. To solve the problem, a nonstationary nonlinear solver of gas dynamic processes (Siemens STAR$\mathrm{CCM}+$ ) was used, which allows to evaluate the correctness of the problem statement, significantly reducing the cost of full-scale tests. The paper considers the heating of a dimensional two-section tank in the layout of the cementing unit on the chassis with a triplex high-pressure pump and a drive from the power take-off box on the gear box of the chassis engine. The exhaust pipe structurally passes inside the measuring tank. According to the research results obtained graphic dependences of temperature change of liquid measuring cups to control points, the distribution of temperature field of the liquid in a volumetric tank, distribution of the temperature field of the surrounding air, stream lines and velocity field of the ambient air and the exhaust gases of internal combustion engines. The results of the calculations clearly show that the application of the method of heating the measuring capacity by entering the exhaust pipe directly into the liquid can be considered effective.
\end{abstract}

\section{Introduction}

With the increasing rates of oil and gas-bearing territories development of the Northern and Arctic latitudes of the country, where hydrocarbon reserves are difficult to recover, oil composition is heavy and viscous with accompanying fatty gases, ensuring a guaranteed plus temperature of the process fluid in the process of drilling and overhaul of wells is one of the priorities in the development of equipment for this work [1-3]. The use of water treatment heating systems is impossible in the conditions of territorial separation of wells and their inaccessibility, in connection with which, today, mobile Autonomous liquid heating systems for oil and gas fields are still relevant. One variant of such systems is the use of hot exhaust gases of chassis engines or deck internal combustion engines of pumping units to heat the liquid in measuring tanks. At all technological processes of liquid preparation, purging and drilling systems, liquid of hydraulic fracturing, the temperature of

\footnotetext{
*Corresponding author: spu-58.2@donstu.ru
} 
system cannot be lower than a critical point of the main component-water, namely $4{ }^{\circ} \mathrm{C}$. The TNK-BP standard "compliance with quality control during hydraulic fracturing" in the paragraph 3.2 requires: "Storage, transportation, testing and injection of all liquid reagents shall be carried out at the temperature bigger than $15^{\circ} \mathrm{C}$ regardless weather conditions". At all types of liquid preparation, purging systems and systems of drilling and washing solutions, the temperature of system shall not be lower than $8-10{ }^{\circ} \mathrm{C}[4,5]$.

One of the most common units for completion of oil and gas wells is the cementing unit CA-320A. The description of the unit mentions the use of exhaust gas system for heating [6]. In the operating manual "Pumping Units UNB-1000, UNB-800, UNP-630" (VNIINEFTNASh) and the operating manual "Cementing hydraulic fracturing unit ACF1050 (UPETROM), there are references to purge drainage systems of the suction manifold and valve boxes of the hydroblock. The instruction to "Installation of two-pump mobile UNP2-320x40" (Concern) points at work with "system of drying and heating" and that they are separately allocated. Thus, the use of internal combustion engine exhaust gases for heating the equipment used in modern pumping units, and the task of studying the effectiveness of such systems is relevant.

\section{Numerical simulations}

In this paper, an attempt is made to analyze the efficiency of heating the dimensional capacity from the exhaust system of the internal combustion engine, on the example of widespread installations CA-320, UNB, ACF, in the variant of the exhaust pipe directly in the dimensional tank. At the same time, the use of numerical methods of research allows us to assess the correctness of the problem statement and significantly reduce the cost of fullscale tests or completely prove the design and technological failure of the problem. In the absence of statistical data on the problem under the study, the results of numerical methods narrow the range of natural problems. To solve the problem, a non-stationary nonlinear solver of gas-dynamic processes (Siemens STAR-CCM+) was used, which allows to evaluate the correctness of the problem statement, significantly reducing the costs of fullscale tests.

For the numerical study, the problem of dimensional two-section tank heating in the layout of the cementing unit on KAMAZ 43118 chassis with a SIN-32 triplex high-pressure pump [7] and a drive from the take-off power box was chosen. Measuring capacity is installed in the area of the rear chassis trolley with a volume of $2 \times 2 \mathrm{~m}^{3}$. The design of the measuring tank is an all-welded sheet, the bottom of which has a slope towards the bottom valves. The exhaust pipe (heating pipe) enters the right tank from the bottom, passes into the left tank and up, to compensate the temperature stresses, parts of the pipes are connected by means of bellows.

The study was carried out for the conditions of the unit operation at the field, using the following assumptions: the pump unit is stationary, the ambient temperature (air) is plus 5 ${ }^{\circ} \mathrm{C}$, the wind speed is $1.0 \mathrm{~m} / \mathrm{s}$, the liquid in both sections of the measuring capacity with a density of $1100 \mathrm{~kg} / \mathrm{m} 3$, the liquid temperature in the measuring capacity is plus $5^{\circ} \mathrm{C}$. In the calculated model the convection heat type between the measuring container and the ambient air is applied, also it is applied between the part of the measuring container and fluid. To simplify the problem, the air was used in exhaust gases to eliminate the use of a multiphase process solver.

Air density: density- $1.184 \mathrm{~kg} / \mathrm{m} 3$, thermal conductivity- $0.026 \mathrm{~W} / \mathrm{m}-\mathrm{K}$, specific heat$1003.6 \mathrm{j} / \mathrm{kg}-\mathrm{K}$ [8-13]. Parameters of liquid in a dimensional capacity: density-1100 kg/m3, thermal conductivity- $0.569 \mathrm{~W} / \mathrm{m}-\mathrm{K}$, specific heat- $4217 \mathrm{j} / \mathrm{kg}-\mathrm{K}[8-13]$. 
Material parameters of the steel hull measuring cups and duct exhaust system: density $7832 \mathrm{~kg} / \mathrm{m} 3$, thermal conductivity $-63.9 \mathrm{~W} / \mathrm{m}-\mathrm{K}$, specific heat $-434.0 \mathrm{j} / \mathrm{kg}-\mathrm{K}$ [8-13], thickness of the hull measuring cups $-4 \mathrm{~mm}$, thickness of pipe exhaust system $-3 \mathrm{~mm}$.

The exhaust gas temperature at the output of the collector is $450{ }^{\circ} \mathrm{C}$, the exhaust gas velocity at the outlet of the collector is $35 \mathrm{~m} / \mathrm{s}$ [14-16]. The calculated idealized scheme is presented in the figure 1.

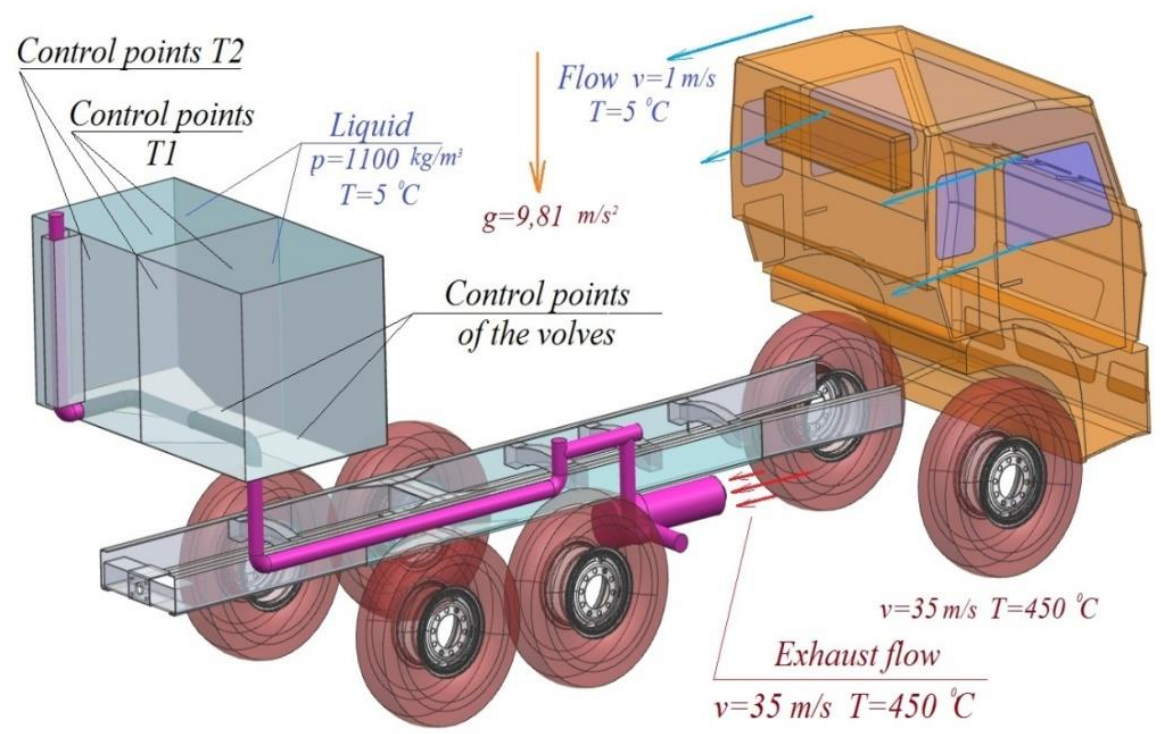

Fig. 1. The calculation scheme.

The calculation was made from the operating conditions of the engine 1800 seconds ( 30 min). Liquid temperature control points were obtained for the left and right side of the measuring vessel at the bottom valves at a distance of $200 \mathrm{~mm}$ from the bottom, at a distance of $1000 \mathrm{~mm}$ from the bottom T1. Graphs of fluid temperature changes during the operation of the internal combustion engine for 30 minutes are shown in the figure 2, temperature fields are shown in figures 3 and 4.

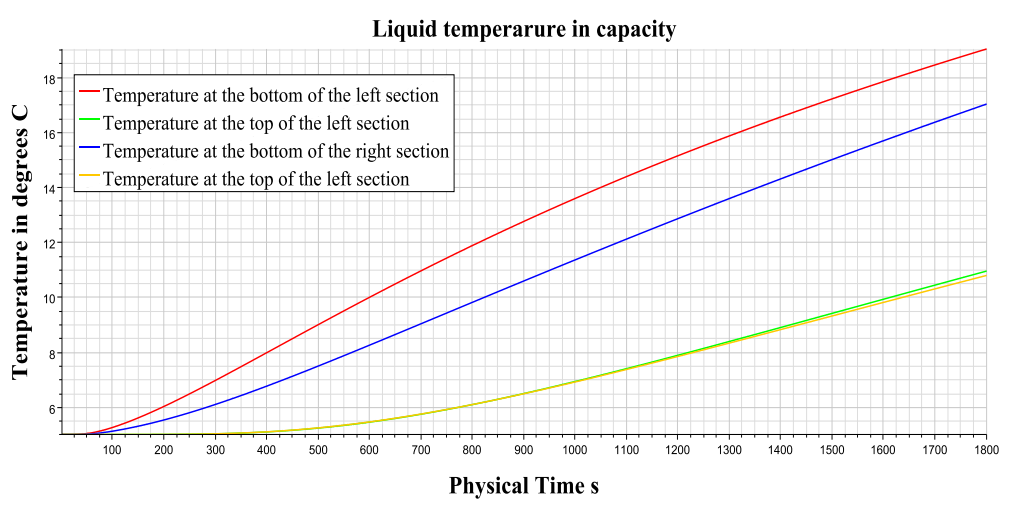

Fig. 2. Graph of liquid temperature change in the measuring capacity at the control points. 


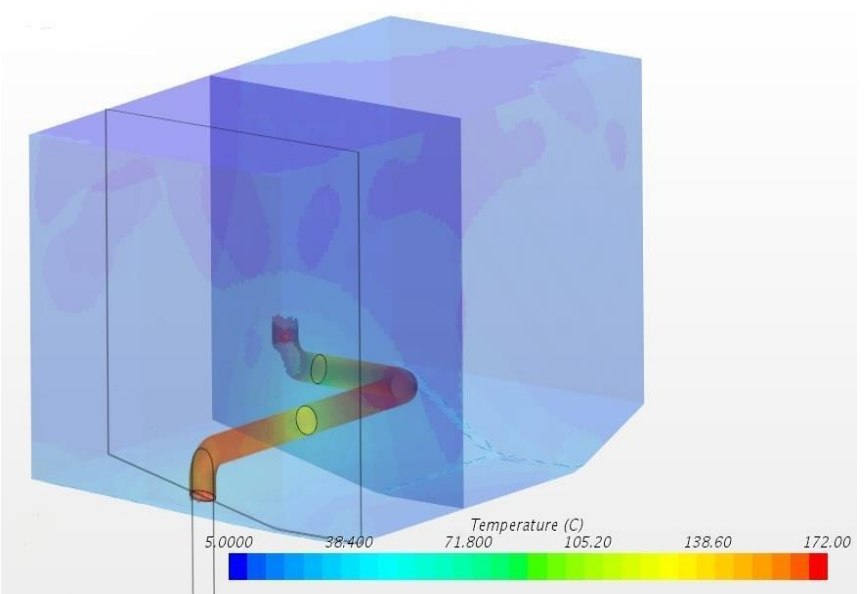

Fig. 3. Distribution of the liquid temperature field in the measuring tank (left view).

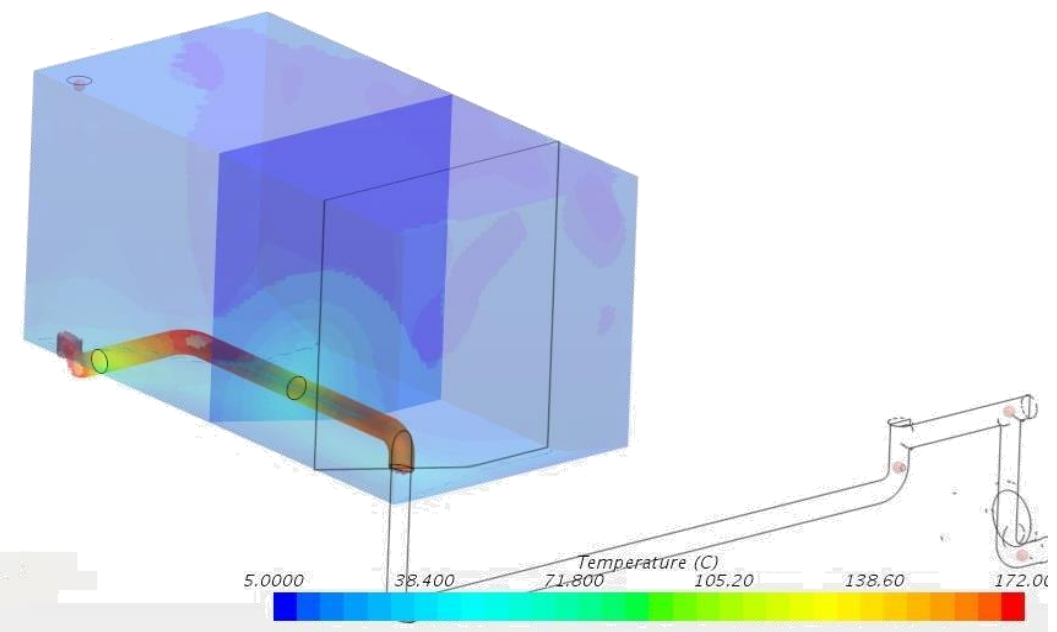

Fig. 4. Distribution of the liquid temperature field in the measuring tank (right view).

\section{Discussion of results and conclusions}

The results of calculations clearly show that for 30 minutes of the internal combustion engine operation and convection heat exchange between the hot exhaust pipe and the liquid in the measuring tank at the control points at the bottom valves, the liquid warmed up to 19 ${ }^{\circ} \mathrm{C}$ in the left compartment and to $17{ }^{\circ} \mathrm{C}$ in the right compartment at the upper control points at the height of $1000 \mathrm{~mm}$ from the bottom of the liquid warmed up to $11^{\circ} \mathrm{C}$. Thus, the application of the measuring capacity heating method by entering the exhaust pipe directly into the liquid can be considered effective.

In conclusion, it should be noted that in order to obtain a more complete picture of the efficiency of hot exhaust gases use of the internal combustion engine, it is necessary to analyze the possibilities for heating with the help of a high-pressure pump and a water supply pump, since their preparation for operation and maintenance in working condition, 
at low temperatures, is an important factor in terms of performance of the equipment entire complex.

\section{References}

1. A. E. Kontorovich, M. I. Epov, L. M. Burshtein. et al., Russian Geology and Geophysics, 51, 3-11 (2010). https://doi.org/10.1016/j.rgg.2009.12.003

2. Ø. Harsem, A. Eide, K. Heen, Energy Policy, 39, 8037-8045 (2011). https://doi.org/10.1016/j.enpol.2011.09.058

3. A. Necci, S. Tarantola, B. Vamanu, Ocean Engineering, 1851, 12-26 (2019). https://doi.org/10.1016/j.oceaneng.2019.05.021

4. Y. Kuwayama, S. Olmstead, A. Krupnick, Curr Sustainable Renewable Energy Rep, 2, 17-24 (2015). https://doi.org/10.1007/s40518-014-0023-4

5. Vladimirova, T., Manakov, A., Sokolov, V. Conceptual framework of economic reliability of production processes MATEC Web of Conferences 2018 216, 02008, DOI: $10.1051 /$ matecconf $/ 201821602008$

6. V. N. Stepanov, S. O. Kireev, M. V. Korchagina, et al., Chem Petrol Eng, 55, 829-834 (2020). https://doi.org/10.1007/s10556-020-00700-3

7. S. O. Kireev, S. L. Nikishenko, B. N. Vasil'ev, et al., Chem Petrol Eng, 52, 332-338 (2016). https://doi.org/10.1007/s10556-016-0195-4

8. Z. Kovziridze, Journal of Electronics Cooling and Thermal Control, 8, 49-54 (2018). doi: $10.4236 /$ jectc.2018.84004.

9. A.V. Malyukov, N. I. Mikheev, V. M. Molochnikov, Instrum Exp Tech, 59, 159-161 (2016). https://doi.org/10.1134/S0020441216010073

10. L. A. Fomenko, L. G. Lovtsova, J. Synch. Investig., 4, 179-182 (2010). https://doi.org/10.1134/S1027451010010271

11. M. Vasilyeva, M. Babaei, E. T. Chung. et al., Applied Mathematical Modelling, 67, 159-178 (2019). https://doi.org/10.1016/j.apm.2018.10.025

12. Zhigang Zhang, Tianxing $\mathrm{Xu}$, Wenxiu Li. et al., Chinese Journal of Chemical Engineering, 19, 1066-1068 (2011). https://doi.org/10.1016/S1004-9541(11)60093-1

13. M. A. Chernysheva, Y. F. Maydanik, International Journal of Heat and Mass Transfer, 131, 442-449 (2019). https://doi.org/10.1016/j.ijheatmasstransfer.2018.11.034

14. M. Bharathiraja, R. Venkatachalam, N. Tiruvenkadam, Transportation Research Part D: Transport and Environment, 49, 291-300 (2016). https://doi.org/10.1016/j.trd.2016.10.028

15. R. Thakar, S. Bhosle, S. Lahane, Procedia Manufacturing, 20, 372-376 (2018). https://doi.org/10.1016/j.promfg.2018.02.054

16. K. Theinnoi, W. Temwutthikun, T. Wongchang. et al., Energy Procedia, 152, 875-882 (2018). https://doi.org/10.1016/j.egypro.2018.09.257 